\title{
What Is the Earliest Non-Invasive Malignant Lesion of the Larynx?
}

\author{
Alfio Ferlito ${ }^{a}$ Claudio Doglioni $^{b}$ Alessandra Rinaldo ${ }^{a}$ \\ Kenneth O. Devaneyc \\ aDepartment of Otolaryngology, Head and Neck Surgery, University of Udine, Italy; bivision of Pathology, \\ Belluno Hospital, Belluno, Italy; ' Department of Pathology, University of Michigan, Ann Arbor, Mich., USA
}

Cancer of the larynx constitutes $1-2 \%$ of all malignancies diagnosed annually worldwide and represents the most common head and neck malignancy in the United States, as recently reported by the National Cancer Data Base [1].

Survival in patients with laryngeal cancer is dependent on the stage and site of tumour and its phenotype. It is obviously difficult, or even impossible, to control faradvanced laryngeal cancer, and it is therefore essential to concentrate on the initial steps in tumour development in order to facilitate early detection and timely implementation of suitable therapy [2].

Neoplastic development in laryngeal epithelium, as with many other epithelial cancers, is a multistep process driven by accumulating multiple and specific genetic alterations, involving oncogenes and tumour suppressor genes $[3,4]$.

The first morphologically unequivocal recognizable step is represented by intraepithelial abnormalities, such as dysplasia and carcinoma in situ. However, adjacent apparently normal squamous epithelium may already harbour the initial genetic abnormalities leading to malignant transformation.

Early detection appears to be the best and only chance to improve the therapeutic results of laryngeal cancer. Therefore, it is necessary to recognize the initial intraepi-

\begin{tabular}{ll}
\hline KARGER & ( 2000 S. Karger AG, Basel \\
Fax +4161306 1234 & 0301-1569/00/0622-0057\$17.50/0 \\
$\begin{array}{l}\text { E-Mail karger@karger.ch } \\
\text { www.karger.com }\end{array}$ & $\begin{array}{l}\text { Accessible online at: } \\
\text { www.karger.com/journals/orl }\end{array}$
\end{tabular}

thelial neoplastic lesions. What is the earliest non-invasive malignant lesion of the larynx? To answer this question, it may be best to begin by explaining what early cancer is.

In our practice, we use the term 'early cancer' to mean a very precisely defined entity, namely, a minimally invasive pathologic and biologic entity which does not invade muscular or cartilaginous structures, but which nevertheless possesses a (small but real) potential for metastasizing. Of necessity, then, such an 'early' cancer is confined to the lamina propria and, as noted above, can be no more than a minimally invasive lesion [5].

In terms of the surface area of mucosa it may involve in a given patient, however, early cancer of the larynx may be a surprisingly extensive lesion, giving rise on occasion to a so-called 'carpet' or 'superficial extending'carcinoma. The critical distinction which we would advocate, however, calls for restriction of the use of the diagnostic term 'early cancer' to lesions in this 'middle ground': lesions which extend further than a purely intraepithelial proliferation (which, by definition, would be delimited by a basement membrane), yet less extensive than those proliferations which reach into adjacent skeletal muscle or cartilage. As such, we do not believe that early cancers are either in situ or T2/T3 lesions [5].
Alfio Ferlito, MD

Department of Otolaryngology, Head and Neck Surgery

University of Udine, Policlinico Città di Udine

Viale Venezia 410

I-33100 Udine (Italy) 
Table 1. Natural history of laryngeal cancer

\begin{tabular}{|c|c|c|c|c|c|}
\hline & Definition & Extension & Morphology & DNA ploidy & Genetic alterations \\
\hline Normal epithelium & & & normal & normal & absent \\
\hline Early genetic alterations & & & normal & normal & $9 \mathrm{p} 21(\mathrm{p} 16)$ \\
\hline LIN & $\begin{array}{l}\text { intraepithelial abnormalities } \\
\text { dysplasia } \\
\text { (intraepithelial neoplasia, } \\
\text { squamous intraepithelial } \\
\text { neoplasia, severe } \\
\text { squamous atypia) }\end{array}$ & $\begin{array}{l}\text { confined to the } \\
\text { epithelium }\end{array}$ & abnormal & may be aneuploid & $\begin{array}{l}17 \mathrm{p}(\mathrm{p} 53), 3 \mathrm{p} 14 \\
\text { telomerase activity }\end{array}$ \\
\hline Invasive cancer & & & abnormal & frequently aneuploid & $\begin{array}{l}\text { 11q13 (cyclin D1), } \\
13 \mathrm{q}\end{array}$ \\
\hline Early & mucosal cancer & $\begin{array}{l}\text { confined to the lamina } \\
\text { propria }\end{array}$ & & & \\
\hline $\begin{array}{l}\text { Deeply } \\
\text { Metastatic }\end{array}$ & non-limited mucosal cancer & $\begin{array}{l}\text { confined to the larynx } \\
\text { extending to the cervical } \\
\text { lymph nodes, presence of } \\
\text { distant metastases }\end{array}$ & & & $8 \mathrm{p} 23,5 \mathrm{p}, 4 \mathrm{q}$ \\
\hline
\end{tabular}

Problems with such a terminology are legion, of course. Recognition of the fact that there actually appears to be a continuum - stretching from squamous dysplasia to bulky, deeply and widely invasive T3 cancers - has made it easy for many observers to use a variety of terms interchangeably. As a result, one speaker may be describing a cartilage invasive tumour while another speaks of a noninvasive intraepithelial proliferation, both speakers using confusingly similar or overlapping descriptions for the respective processes.

From a biologic point of view, such loose terminology is readily defended. After all, when dealing with a continuum of disease (analogous to the continuum of disease in the colon, ranging from the adenomatous polyp to an invasive adenocarcinoma), how can a surgeon (on physical examination) or a surgical pathologist (on light microscopy) make unerring divisions in such a continuous process which resists being broken up into neatly defined segments? From the surgical pathologist's perspective, for example, the fear always exists that a given section showing an intraepithelial lesion has just failed to sample an immediately adjacent region of invasive tumour. It is not hard to see why some 'slipperiness' of nosology may be useful, both to avoid overstating the precision with which routine diagnoses can be made, and to acknowledge the fact that this is a continuum of disease.

This sort of explanation does not, however, provide much comfort to the practising surgeon, who must make a series of judgements affecting just a single patient: Do nothing now and follow? Operate at once? Irradiate?
Learning that patient $X$ has squamous dysplasia, while patient $Y$ has severe squamous atypia, while patient $Z$ has laryngeal intraepithelial neoplasia (LIN), the surgeon may wonder whether he/she is obliged to craft three different treatment plans, one for each apparently distinct and different disease.

In fact, of course, these three designations probably (depending on the mental picture the pathologist has in mind of the nosology of this disease process) all describe the same thing. In the hope of bringing some clarity to this murky area, we recommend this approach: LIN should be used to refer to lesions confined by the basement membrane which are marked by light microscopic features of malignancy. These morphological aspects can also be accompanied by aneuploidy of the affected cells by DNA ploidy analysis [6], and frequent immunohistochemical overexpression of $\mathrm{p} 53$ protein [7]. These simple methods permit to detect some of the most frequent genetic abnormalities underlying this malignant process. Defined in this fashion, LIN covers dysplasia, intraepithelial neoplasia, squamous intraepithelial neoplasia, and severe squamous atypia.

As seen in table 1, it is not our purpose to minimize the significance of the 'continuum of disease' concept as it relates to the development of laryngeal cancers. Rather, we seek to impose some discipline on a terminology which while biologically defensible as truthful [8], may at times obfuscate the clinical decision-making process.

This is not to ignore the fact that we may be asking more of surgical pathology than it can always deliver. 
Take, for example, the often used/abused diagnosis of 'atypia'. This may mean nothing of any significance to one observer, and a full-blown carcinoma in situ confined only by the delicate basement membrane to another observer. This apparently wide discrepancy in usage illustrates a simple truth: that recognition by light microscopy of intraepithelial lesions which will, if untreated, progress to invade adjacent structures is not always an easy, reproducible task. It is no wonder, then, that words of elastic usage are employed to provide some cover for this most challenging difficulty in diagnostic pathology. Were this not a sufficient problem, these difficulties are severely exacerbated when frozen section artifacts are imposed on biopsy tissues.

These 'hard to classify' lesions are, most regrettably, destined to appear with depressing frequency in any large practice; as such, we must acknowledge that - despite our desire to employ as clear a terminology as possible in our own work - there are simply going to be occasions when we cannot resist the temptation to use an imprecise term such as 'atypia' for lack of anything better. When others confront such a problem in their own practices, perhaps the best advice is to do what we do - communicate directly with the surgical pathologist, in an attempt at bringing as much clarity to the matter as is possible, in view of the imperfect tools presently at our disposal.

The diagnosis of LIN, in short, will continue to be a not always entirely reliable process when working with tiny biopsy specimens, at least for the foreseeable future. Lesions which are indeed dysplastic - that is, unequivocal cases of LIN (particularly high grade or full thickness lesions) - should be removed by excision or stripping in most instances. Close and long-term follow-up investigation of these LIN patients is critically important. In particular, an eye should be directed toward seeking out the presence of those sorts of exogenous irritants which might effect changes in epithelial cells which - while lacking a potential for progressing to full-blown invasive cancer may nonetheless mimic the light microscopic appearances of LIN and so prompt a pathologic diagnosis of 'atypia' or other such less than conclusive designation.

In conclusion, laryngeal dysplasia, or LIN, should be recognized as the earliest malignant lesion which already manifests - at both a light microscopic and a molecular level - cancerous features (although, admittedly, its immediate threat to the affected patient is quite limited at that moment in time).

\section{References}

1 Hoffman HT, Karnell LH, Funk GF, Robinson RA, Menck HR: The National Cancer Data Base report on cancer of the head and neck. Arch Otolaryngol Head Neck Surg 1998;124: 951-962.

2 Ferlito A: The natural history of early vocal cord cancer. Acta Otolaryngol (Stockh) 1995; 115:345-347.

3 Califano J, van der Riet P, Westra W, Nawroz H, Clayman G, Piantadosi S, Corio R, Lee D, Greenberg B, Koch W, Sidransky D: Genetic progression model for head and neck cancer: Implication for field cancerization. Cancer Res 1996;56:2488-2492.
4 Rowley H: The molecular genetics of head and neck cancer. J Laryngol Otol 1998;112:607612.

5 Ferlito A, Carbone A, DeSanto LW, Barnes L, Rinaldo A, D’Angelo L, Devaney KO: 'Early' cancer of the larynx: The concept as defined by clinicians, pathologists, and biologists. Ann Otol Rhinol Laryngol 1996;105:245-250.
What Is the Earliest Non-Invasive

Malignant Lesion of the Larynx?
6 Crissman JD, Zarbo RJ: Quantitation of DNA ploidy in squamous intraepithelial neoplasia of the laryngeal glottis. Arch Otolaryngol Head Neck Surg 1991;117:182-188.

7 Gorgoulis V, Rassidakis G, Karameris A, Giatromanolaki A, Barbatis C, Kittas C: Expression of p53 protein in laryngeal squamous cell carcinoma and dysplasia: Possible correlation with human papillomavirus infection and clinicopathological findings. Virchows Arch A Pathol Anat Histopathol 1994;425:481-489.

8 Schantz SP: Biologic staging of head and neck cancer. Curr Opin Otolaryngol Head Neck Surg 1993;1:107-113. 